\title{
Asthma, much more than a respiratory disease: influence of depression and anxiety
}

\author{
Rafael Hurtado-Ruzza ${ }^{1,2}$ (1) Óscar Álvarez-Calderón Iglesias ${ }^{1,2}$ (D), Raquel Dacal-Quintas ${ }^{3}$ (1), \\ Ricardo Becerro-de-Bengoa-Vallejo ${ }^{4}$ (1) César Calvo-Lobo ${ }^{4}$ (1), Marta San-Antolín ${ }^{5 *}$ (1), \\ Marta Elena Losa-Iglesias ${ }^{6}$ (D) Daniel López-López ${ }^{1}$
}

\section{SUMMARY}

OBJECTIVE: The goals of this study are to compare self-reported depression and anxiety in subjects diagnosed of asthma and healthy controls. METHODS: We designed a case-control study. Subjects were recruited using a consecutive sampling method from a single institution. Two groups were created: Asthma and healthy controls. Data of medical history and demographic background were collected from the medical record. Self-reported depression level was assessed using Beck's depression inventory (BDI). Self-reported anxiety was measured with the "State-trait anxiety inventory" (STAI).

RESULTS: Fifty-one subjects with asthma, and fifty healthy patients were included in this study. BDI scores $(p<0.001)$ were higher for asthma $(10.22 \pm 7.3)$ than in the control group $(5.2 \pm 6.56)$. STAl state $(p<0.001)$ was higher in asthma $(42.61 \pm 11.5)$ than in controls $(34.88 \pm 9.25)$. STAI trait $(p<0.001)$ showed higher scores in asthma $(43.14 \pm 10.89)$ than in controls $(34.62 \pm 9.19)$.

CONCLUSIONS: These study findings showed that BDI, and STAI trait and state scores are significantly higher in subjects who suffer from asthma than healthy controls.

KEYWORDS: Depression. Anxiety. Asthma.

\section{INTRODUCTION}

Depression and anxiety are considered "common mental disorders". Globally, the total number of people with depression was estimated to exceed 300 million in 2015 (4.5\% of the world's population). Up to nearly $40 \%$ of the population are affected at some point by an anxiety disorder ${ }^{1}$. The consequences of both conditions in terms of loss of health are substantial and have a considerable effect on a patient's health-related quality of life (HRQL). Depression is considered the single largest contributor to global disability around the world. The most common underlying disorder in those who attempt suicide is depression.

Depressive disorders are characterized by symptoms as sadness, loss of interest or pleasure, feelings of worthlessness or guilt, sleep difficulties, fatigue, appetite or weight changes, feelings of tiredness, psychomotor disturbances, poor ability to concentrate, and even suicidality ${ }^{2}$. Depression can be long-lasting or recurrent, causing impairment to daily life activities.

Anxiety is associated with physical and psychological discomfort. All anxiety disorders share common symptoms, such

\footnotetext{
'Universidade da Coruña, Research, Faculty of Nursing and Podiatry, Health and Podiatry Group, Department of Health Sciences - Ferrol, Spain. ${ }^{2}$ Complexo Hospitalario Universitario de Ourense - Ourense, Spain.

${ }^{3}$ Complexo Hospitalario Universitario de Ourense, Pneumology Department - Ourense, Spain.

${ }^{4}$ Universidad Complutense de Madrid, Faculty of Nursing, Physiotherapy, and Podology - Madri, Spain.

${ }^{5}$ Universidad Europea de Madrid, Department of Psychology - Madrid, Spain.

${ }^{6}$ Universidad Rey Juan Carlos, School of Health Sciences - Madrid, Spain.

*Corresponding author: marta.sanantolin@universidadeuropea.es

Received on January 19, 2021. Accepted on January 24, 2021.
} 
as fear, anxiety, and avoidance. Other anxiety-related symptoms include fatigue, restlessness, irritability, sleep disturbances, reduced concentration, lack of memory, and muscle tension. Depression and anxiety often co-occur. Up to $90 \%$ of patients with anxiety develop symptoms of depression, and nearly $85 \%$ of patients with depression show some kind of anxiety symptom ${ }^{3}$.

The prevalence of depression and anxiety is two to three times higher in people with chronic medical conditions than in healthy peopl ${ }^{4}$. People with a long-term condition and depression or anxiety have worse health status than people with depression or anxiety alone, and even than people with any combination of long-term conditions without depression ${ }^{5}$.

Asthma is considered a chronic heterogeneous disease. Its pathogenesis involves various cells and mediators of inflammation, and it is characterized by airway inflammation. It is defined by the history of respiratory symptoms such as wheeze, shortness of breath, chest tightness, and cough that vary over time and in intensity, together with variable expiratory airflow limitation, totally or partially reversible, either spontaneously or due to the action of the medication ${ }^{6}$.

In 2017, the worldwide prevalence of asthma was around $3.5 \%$ with a reported incidence of $0.56 \%{ }^{7}$. Asthma may disturb daily activities, as well as the patient's quality of life $(\mathrm{QoL})^{8}$. It carries an economic burden, due to an often increment of the emergency care use, hospital admission, as well as work absenteeism. In addition, it can potentially cause early disability and premature death. The mean cost per patient per year is high, and can vary among countries, according to Nunes et al, in Europe is \$USD 1,900, different from the USA, in which estimated mean is estimated around \$USD 3,100 . People with asthma are more prone to emotional disorders, even when their symptoms are controlled ${ }^{10}$. Different authors, reported a high prevalence of anxiety and depression ${ }^{11,12}$. Labor et al. reported that $24.5 \%$ of asthma patients were depressed, and $44 \%$ had symptoms of anxiety ${ }^{11}$.

Del Giacco et al, reported that anxiety may be a predisposing factor for developing asthma, and also, having asthma may predispose a higher risk of having an anxiety disorder, establishing the possibility of a bidirectional association between anxiety and asthma ${ }^{13}$.

Besides, anxiety and depression have been associated with increased asthma exacerbations and emergency visits ${ }^{14}$. Depression acts as an independent co-morbid factor in asthma ${ }^{15}$.

We hypothesized that people with asthma, had the worst levels of Self-perceived depression, anxiety trait, and state when compared to healthy people. So, the main objective of this research was to determine self-perceived depression and anxiety trait and state levels in a subset of asthma patients compared to healthy controls.

\section{METHODS}

\section{Study design}

A case-control study of a non-probability consecutive sampling method from a medical center was performed to compare self-assessed depression severity, anxiety trait, and anxiety state in patients diagnosed with asthma and healthy controls. All the data collection was supervised by the same researcher. The guidelines for reporting observational studies, stated by the "Strengthening the Reporting of Observational Studies in Epidemiology" (STROBE) were followed ${ }^{16}$.

This study was approved by the ethics committee of clinic research of Galicia (Spain). The Helsinki declaration as well as all national and international ethical standards for human experimentation were respected ${ }^{17}$. Also, all participants signed the informed consent before their inclusion in the present research.

\section{Analytic analysis}

\section{Sample size calculation}

T-tests for differences between 2 different means were used to determine the sample size calculation by the $G^{*}$ Power 3.1.9.2 software and based on the BDI as the main outcome measurement of a pilot study ( $\mathrm{n}=28$ participants) with 2 groups (mean \pm SD), 14 patients with asthma ( $9.28 \pm 6.16$ points) and 14 healthy controls (4.92 \pm 3.64 points). Furthermore, the followed parameters were used for the sample size calculation with an effect size of $0.86, \alpha$ error of 0.01 , and power (1- $\beta$ error) of 0.90 . Thus, the required total sample size was 84 participants, 42 for each group, necessary to achieve an actual power of 0.901 . Finally, considering a possible $15 \%$ loss to follow-up, a total sample of 98 participants, 49 subjects for each group, was required for the present study.

\section{Participants}

A consecutive sampling method was used to recruit participants from the pneumology department of the Complexo Hospitalario de Ourense (Ourense, Spain). Two groups were established: Asthma (case group) and healthy patients (control group). Asthma patients were diagnosed and classified according to the GEMA (Spanish Group for Asthma Management) guidelines ${ }^{6}$. Healthy matched-paired participants were included, as the control group. The inclusion criteria were being older than 18 years old, agreement to sign informed consent, and lack of history of psychiatric. For the control group, healthy participants older than 18 years old were included, without chronic respiratory disease, or known psychiatric medical history and agreement to sign informed consent. Exclusion criteria: not complying with the inclusion criteria described above. 


\section{Descriptive data}

Descriptive data such as sex, age, weight, height, body mass index (BMI; calculated by the Quetelet index as $\mathrm{kg} / \mathrm{m}^{2}$ ), and smoke habit were collected.

\section{Outcome measurements}

Self-perceived depression, anxiety trait, and state were considered as the primary outcomes.

Self-reported depression was assessed using the "Beck's depression inventory (BDI-II)", which has become one of the most widely used instruments for assessing the severity of depression worldwide. It contains 21 items, scored by a 4-point Likert scale (0-3). The final results range from 0 to 63 points. Greater scores suggest increased depression severity. Scores between 0-10 indicate no signs of depression; 11-16 indicate mild depression; 17-20 indicate borderline depression; 21-30 indicate moderate depression; $31-40$ indicate serious depression; and, 41 or higher indicate extreme depression. Anything over 17 points requires professional treatment ${ }^{18}$. This tool was validated in Spanish, with a Cronbach's $\alpha=0.87$ and a high diagnostic validity $(\mathrm{ROC}=0.91)$ in the general population ${ }^{19}$.

The State-Trait Anxiety Inventory (STAI) is a self-reported scale used for the assessment of anxiety state and trait in research and clinical practice. The STAI consists of two 20-item scales (S-Anxiety measuring anxiety as an emotional state, and T-Anxiety measuring anxiety as a personal characteristic or trait $)^{20}$. Each item is scored by a 4-point Likert scale (1-4). Spanish version of the STAI was used. The final score was converted to a digit $(0-80)$ as described for Buela-Casal, to be uniform with the original Y-version of the $\mathrm{STAI}^{21}$. Higher scores suggest higher levels of anxiety. This test has a good internal consistency, with a Cronbach's $\alpha=0.92$ for anxiety state $(95 \% \mathrm{IC} 0,91-0,93)$ and a Cronbach's $\alpha=0.91$ for anxiety trait (95\%IC 0.90-0.92.) $)^{22}$ and a Test-retest reliability coefficients on initial development ranged from 0.31 to $0.86^{20}$.

\section{Statistical analysis}

Statistical analyses were performed by the SPSS 24.0 version (IBM-Windows; Armonk-NY: IBM Corp) using an $\alpha$ error of 0.01 in conjunction with a $99 \%$ confidence interval (CI).

Considering quantitative data, the test of KolmogorovSmirnov was applied to determine normality distribution. All data were described by the mean \pm standard deviation (SD) and range (minimum-maximum values). Regarding the parametric data (Kolmogorov-Smirnov $\mathrm{p} \geq 0.05$ ), between-groups differences were compared by the Student $t$-tests for independent samples, and for the non-parametric data (KolmogorovSmirnov $\mathrm{p}<0.05)$, between-groups differences were compared by the Mann-Whitney $U$ tests for independent samples.

For categorical data, frequencies were used to describe these data values and categorical between-groups differences were analyzed by the Fisher exact tests for the age dichotomous variable and the Chi-square $\left(\chi^{2}\right)$ test for the depression categories polytomous variable using bar graphs to show this distribution.

\section{RESULTS}

The study population included 101 participants, 37 men and 64 women. 11 participants (10.9\%) were smokers, 21 (20.8\%) former smokers, and $69(68.3 \%)$ non-smokers. The control group was formed by 50 healthy participants, $64 \%$ female and $36 \%$ male, with a mean age of $42.84 \pm 15.69$. They were not having chronic medication. In the asthma group, there were 51 patients, $62.7 \%$ female and $37.3 \%$ male, with a mean age of $59.76 \pm 17.7$ years. According to Table 1 , there were statistically

Table 1 Sociodemographic and clinical characteristics of the sample population.

\begin{tabular}{|c|c|c|c|c|}
\hline & Sample & Control & Asthma & \\
\hline & $\begin{array}{c}\text { Mean } \pm \text { SD (range) } \\
n=52\end{array}$ & $\begin{array}{c}\text { Mean } \pm \text { SD (range) } \\
n=50\end{array}$ & $\begin{array}{c}\text { Mean } \pm \text { SD (range) } \\
\mathrm{n}=51\end{array}$ & p-value \\
\hline Age (years) & $\begin{array}{c}51.39 \pm 18.45 \\
(18-95)\end{array}$ & $\begin{array}{c}42.84 \pm 15.69 \\
(19-83)\end{array}$ & $\begin{array}{c}59.76 \pm 17.17 \\
(18-95)\end{array}$ & $<0.001$ * \\
\hline Weight (Kg) & $\begin{array}{c}72.59 \pm 13.83 \\
(43-115)\end{array}$ & $\begin{array}{l}70.37 \pm 13.9 \\
(47-115)\end{array}$ & $\begin{array}{l}74.76 \pm 13.51 \\
(43-109)\end{array}$ & $0.111^{\dagger}$ \\
\hline Height (m) & $\begin{array}{c}1.66 \pm 0.1 \\
(1.45-1.90)\end{array}$ & $\begin{array}{c}1.69 \pm 0.92 \\
(1.50-1.89)\end{array}$ & $\begin{array}{c}1.63 \pm 0.10 \\
(1.45-1.90)\end{array}$ & $0.003^{*}$ \\
\hline BMI $\left(\mathrm{Kg} / \mathrm{m}^{2}\right)$ & $\begin{array}{c}26.31 \pm 4.79 \\
(17.59-45.78)\end{array}$ & $\begin{array}{c}24.48 \pm 3.42 \\
(17.59-33.79)\end{array}$ & $\begin{array}{c}28.09 \pm 5.27 \\
(18.13-45.78)\end{array}$ & $<0.001$ * \\
\hline Sex (female/male) & $64 / 37$ & $32 / 18$ & $32 / 19$ & $1.000^{\ddagger}$ \\
\hline Smoker (no/yes/former) & $69 / 11 / 21$ & $38 / 7 / 5$ & $31 / 4 / 16$ & $0.026^{\S}$ \\
\hline
\end{tabular}

BMI: body mass index; SD: standard deviation; $p<0.01$ with a $99 \%$ confidence interval was considered statistically significant. *Mann-Whitney Utest was used. 'Student $t$-test for independent samples test was used. ${ }^{*}$ Fisher exact test was used. ${ }^{5}$ Chi-squared $\left(\chi^{2}\right)$ test was used. 
Table 2. Depression and anxiety score differences between asthma and healthy participants.

\begin{tabular}{|c|c|c|c|c|}
\hline & Sample & Control & Asthma & \multirow[b]{2}{*}{$\mathrm{p}$-value } \\
\hline & $\begin{array}{c}\text { Mean } \pm \text { SD (range) } \\
n=52\end{array}$ & $\begin{array}{c}\text { Mean } \pm \text { SD (range) } \\
n=50\end{array}$ & $\begin{array}{c}\text { Mean } \pm \text { SD (range) } \\
n=51\end{array}$ & \\
\hline STAI-State & $\begin{array}{c}38.78 \pm 11.10 \\
(21-71)\end{array}$ & $\begin{array}{l}34.88 \pm 9.25 \\
(21-66)\end{array}$ & $\begin{array}{l}42.60 \pm 1.50 \\
(21-71)\end{array}$ & $<0.001 *$ \\
\hline STAI-Trait & $\begin{array}{l}38.92 \pm 10.91 \\
(20-69)\end{array}$ & $\begin{array}{c}34.62 \pm 9.19 \\
(20-65)\end{array}$ & $\begin{array}{c}47.13 \pm 10.89 \\
(20-69)\end{array}$ & $<0.001^{\dagger}$ \\
\hline BDI & $\begin{array}{l}7.73 \pm 7.35 \\
(0-36)\end{array}$ & $\begin{array}{l}5.20 \pm 6.56 \\
(0-36)\end{array}$ & $\begin{array}{l}10.21 \pm 7.30 \\
(0-27)\end{array}$ & $<0.001^{\dagger}$ \\
\hline
\end{tabular}

BDI: beck depression inventory; SD: standard deviation; STAI: state-trait anxiety inventory; $p<0.01$ with a $99 \%$ confidence interval was considered statistically significant. *Student $t$-test for independent samples test was used. ${ }^{+}$Mann-Whitney $U$ test was used.

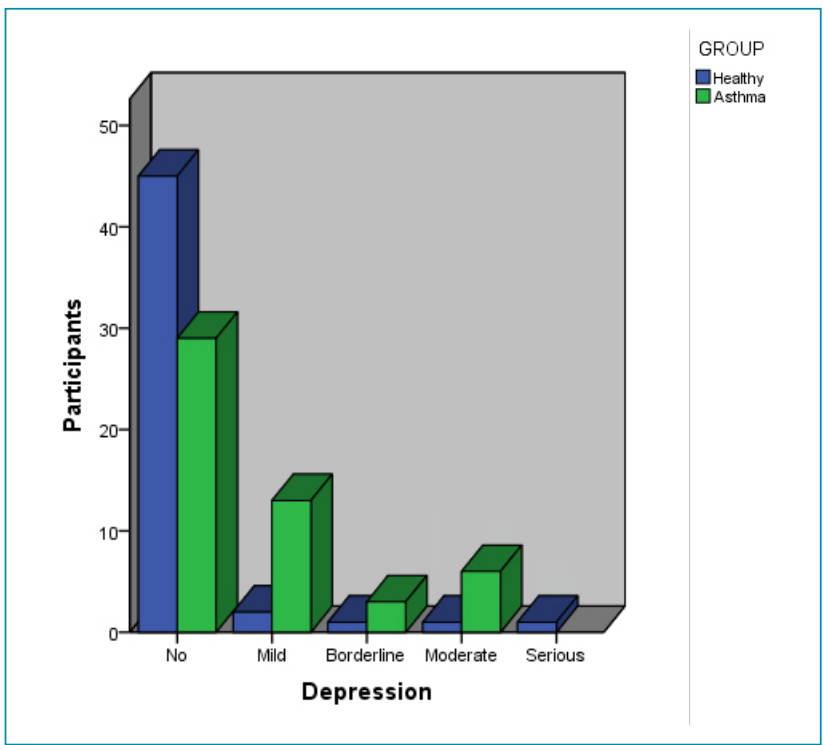

Figure 1. Depression categories between asthma and healthy subjects.

significant differences $(\mathrm{p}<0.01)$ between asthma and healthy participants for age, height and BMI, but not for weight, sex and smoker habits $(\mathrm{p}>0.01)$.

Regarding Table 2, state and trait anxiety as well as anxiety scores were greater in patients who suffer from asthma with respect to healthy participants, showing statistically significant differences $(\mathrm{p}<0.001)$. In addition, the Chi-squared $\left(\chi^{2}\right)$ test showed statistically significant differences $(\mathrm{p}=0.002)$ detailing more presence of mild, borderline, and moderate depression categories in patients with asthma versus healthy subjects according to Figure 1.

\section{DISCUSSION}

Psychological issues are very common in asthma and have a significant impact on quality of life, even if the asthma symptoms are under adequate clinical control ${ }^{8,23}$.
In the present study, we found a higher self-reported anxiety state and trait scores in patients with asthma compared to healthy people, consistent with the data previously published ${ }^{24,25}$. Also found higher BDI scores in asthma patients, compared to controls and a direct correlation between the severity of depressive symptoms and asthma severity. The exact connection between asthma and anxiety/depression is still not fully explained. Regarding anxiety in asthma, even when disease control is reached, these patients could experience continuous distress, having presented the risk of future exacerbations, and fear of a crisis and reduced pulmonary function. Chronic psychological distress may cause a pro-inflammatory condition and be associated with increased superoxide and cytokine and leukocyte production. According to Veres et al., neurokinins and P substance (asthma pulmonary neurogenic inflammation byproducts) have a direct action on the central nervous system, inducing anxiety states ${ }^{26}$.

Regarding depression and asthma, as a possible pathophysiological mechanism, Marini et al. described that the pro-inflammatory state noted in certain asthma phenotypes is similar to that induced by pro-inflammatory cytokine treatments in humans such as corticosteroids, long known to be associated with depressive symptoms ${ }^{27}$. Also, hypothalamic-pituitary-adrenal axis dysregulation, noted in major depression, have been described in asthma as a result of the inhaled corticosteroids ${ }^{28,29}$.

This study had some limitations and should be taken into consideration in future studies. First, to recruit participants a consecutive sampling method was used and could be improved. Second, a larger sample size could be necessary to achieve more reliable results.

\section{CONCLUSIONS}

Asthma subjects showed higher scores of self-reported depression, anxiety state, and anxiety trait than controls. 


\section{AUTHORS" CONTRIBUTIONS}

RHR: Conceptualization, Data curation, Formal analysis, Investigation, Methodology, Supervision, Writing - original draft, Writing - review \& editing. ÓÁCI: Conceptualization, Data curation, Formal analysis, Investigation, Methodology, Supervision, Writing - original draft, Writing - review \& editing. RDQ: Conceptualization, Data curation, Formal analysis, Investigation, Methodology, Supervision, Writing - original draft, Writing - review \& editing. RBBV: Conceptualization, Formal analysis, Investigation, Methodology, Supervision,
Writing - original draft, Writing - review \& editing. CCL: Conceptualization, Formal analysis, Investigation, Methodology, Supervision, Writing - original draft, Writing - review \& editing. MSA: Conceptualization, Formal analysis, Investigation, Methodology, Supervision, Writing - original draft, Writing review \& editing. MELI: Conceptualization, Formal analysis, Investigation, Methodology, Supervision, Writing - original draft, Writing - review \& editing. DLL: Conceptualization, Formal analysis, Investigation, Methodology, Supervision, Writing - original draft, Writing - review \& editing.

\section{REFERENCES}

1. Bandelow B, Michaelis S. Epidemiology of anxiety disorders in the 21st century. Dialogues Clin Neurosci. 2015;17(3):327-35. https://doi.org/10.31887/DCNS.2015.17.3/bbandelow

2. Tolentino JC, Schmidt SL. DSM-5 criteria and depression severity: implications for clinical practice. Front Psychiatry. 2018;9450. https://doi.org/10.3389/fpsyt.2018.00450

3. Möller HJ, Bandelow B, Volz HP, Barnikol UB, Seifritz E, Kasper S. The relevance of 'mixed anxiety and depression' as a diagnostic category in clinical practice. Eur Arch Psychiatry Clin Neurosci. 2016;266(8):725-36. https://doi.org/10.1007/ s00406-016-0684-7

4. Katon WJ. Epidemiology and treatment of depression in patients with chronic medical illness. Dialogues Clin Neurosci. 2011;13(1):723. https://doi.org/10.31887/DCNS.2011.13.1/wkaton

5. Moussavi S, Chatterji S, Verdes E, Tandon A, Patel V, Ustun B. Depression, chronic diseases, and decrements in health: results from the World Health Surveys. Lancet. 2007;370(9590):851-8. https://doi.org/10.1016/S0140-6736(07)61415-9

6. Plaza Moral V, Comité Ejecutivo de GEMA. GEMA4.0. Guía española para el manejo del asma. Arch Bronconeumol. 2015;51(Suppl 1):2-54. https://doi.org/10.1016/S03002896(15)32812-X

7. Mattiuzzi C, Lippi G. Worldwide asthma epidemiology: insights from the Global Health Data Exchange database. Int Forum Allergy Rhinol. 2020;10(1):75-80. https://doi.org/10.1002/ alr.22464

8. ÂGJ, Mendes AZ, Carvalho FDW, de Paula MAR, Brasil TG. The impact of asthma on quality of life and anxiety: a pilot study. J Asthma. 2019;56(6):680-5. https://doi.org/10.1080 /02770903.2018.1486854

9. Nunes C, Pereira AM, Morais-Almeida M. Asthma costs and social impact. Asthma Res Pract. 2017;3:1. https://doi. org/10.1186/s40733-016-0029-3

10. Lavoie KL, Bacon SL, Barone S, Cartier A, Ditto B, Labrecque M. What is worse for asthma control and quality of life: depressive disorders, anxiety disorders, or both? Chest. 2006;130(4):103947. https://doi.org/10.1378/chest.130.4.1039

11. Labor S, Labor M, Jurić I, Vuksić Z. The prevalence and pulmonary consequences of anxiety and depressive disorders in patients with asthma. Coll Antropol. 2012;36(2):473-81. PMID: 22856233

12. Goodwin RD, Jacobi F, Thefeld W. Mental disorders and asthma in the community. Arch Gen Psychiatry. 2003;60(11):1125-30. https://doi.org/10.1001/archpsyc.60.11.1125
13. Del Giacco SR, Cappai A, Gambula L, Cabras S, Pera S, Manconi PE, et al. The asthma-anxiety connection. Respir Med. 2016;120:44-53. https://doi.org/10.1016/j.rmed.2016.09.014

14. Ahmedani BK, Peterson EL, Wells KE, Williams LK. Examining the relationship between depression and asthma exacerbations in a prospective follow-up study. Psychosom Med. 2013;75(3):30510. https://doi.org/10.1097/PSY.0b013e3182864ee3

15. Ferro MA, Van Lieshout RJ, Scott JG, Alati R, Mamun AA, Dingle K. Condition-specific associations of symptoms of depression and anxiety in adolescents and young adults with asthma and food allergy. J Asthma. 2016;53(3):282-8. https:// doi.org/10.3109/02770903.2015.1104694

16. von Elm E, Altman DG, Egger M, Pocock SJ, Gøtzsche PC, Vandenbroucke JP. The Strengthening the Reporting of Observational Studies in Epidemiology (STROBE) Statement: guidelines for reporting observational studies. Int J Surg. 2014;12(12):1495-9. https://doi.org/10.1016/j.jisu.2014.07.013

17. Holt GR. Declaration of Helsinki-the world's document of conscience and responsibility. South Med J. 2014;107(7):407. https://doi.org/10.14423/SMJ.0000000000000131

18. Beck A, Steer RA, Brown GK. Manual for the Beck Depression Inventory, 2nd ed. San Antonio: Psychological Corporation; 1996.

19. San J. 50 Years of the Beck depression inventories: recommendations for using the spanish adaptation of the BDI-II in clinical practice. Papeles del Psicólogo. 2013;34(3):161-8. Available from: https:// www.researchgate.net/publication/278784843_50_Years_ of_the_beck_depression_inventory_Tips_for_using_spanish_ adaptation_the_BDI-II_in_clinical_practice

19. Sanz J. 50 years of the Beck depression inventories: recommendations for the use of the spanish adaptation of the BDI-II in clinical [dissertation] [cited on 2019 Aug 14]. Madrid: Universidad Complutense de Madrid https://www. pearsonclinical.es/Portals/0/DocProductos/13714632902.pdf.

20. Renzi DA. State-trait anxiety inventory. Measurement and Evaluation in Counseling and Development. 1985;18(2):86-9. https://doi.org/10.1080/07481756.1985.12022795

21. Buela-Casal G, Guillén-Riquelme A. Short form of the Spanish adaptation of the State-Trait Anxiety Inventory. Int J Clin Heal Psychol. 2017;17(3):261-8. https://doi.org/10.1016/j.ijchp.2017.07.003

22. Guillén-Riquelme A, Buela-Casal G. Meta-analysis of group comparison and meta-analysis of reliability generalization of the state-trait anxiety inventory questionnaire (STAI). Rev Esp Salud Publica. 2014;88(1):101-12. https://doi.org/10.4321/ S1135-57272014000100007 
23. Robinson R, Barber K, Jones G, Blakey J, Burhan $H$. Exploring the relationship between generalised anxiety/ depression scales and asthma-specific quality of life/control questionnaires in a specialist asthma clinic. J Asthma. 2021;58(7):912-20. https://doi.org/10.1080/02770903.2 020.1744640

24. Tabała K, Wrzesińska M, Stecz P, Kocur J. Personality traits, level of anxiety and styles of coping with stress in people with asthma and chronic obstructive pulmonary disease $-\mathrm{a}$ comparative analysis. Psychiatr Pol. 2016;50(6):1167-80. https://doi.org/10.12740/pp/62726

25. Saito N, Itoga M, Tamaki M, Yamamoto A, Kayaba H. Cough variant asthma patients are more depressed and anxious than classic asthma patients. J Psychosom Res. 2015;79(1):18-26. https://doi.org/10.1016/j.jpsychores.2015.03.011

26. Veres TZ, Rochlitzer S, Braun A. The role of neuro-immune cross-talk in the regulation of inflammation and remodelling in asthma. Pharmacol Ther. 2009;122(2):203-14. https://doi. org/10.1016/j.pharmthera.2009.02.007

27. Marini M, Vittori E, Hollemborg J, Mattoli S. Expression of the potent inflammatory cytokines, granulocyte-macrophagecolony-stimulating factor and interleukin- 6 and interleukin-8, in bronchial epithelial cells of patients with asthma. J Allergy Clin Immunol. 1992;89(5):1001-9. https://doi.org/10.1016/00916749(92)90223-0

28. Zöllner EW, Lombard CJ, Galal U, Hough FS, Irusen EM, Weinberg E. Hypothalamic-pituitary-adrenal axis suppression in asthmatic school children. Pediatrics. 2012;130(6):e1512-9. https://doi.org/10.1542/peds.2012-1147

29. Vreeburg SA, Hoogendijk WJG, DeRijk RH, van Dyck $\mathrm{R}$, Smit JH, Zitman FG, et al. Salivary cortisol levels and the 2-year course of depressive and anxiety disorders. Psychoneuroendocrinology. 2013;38(9):1494-502. https:// doi.org/10.1016/j.psyneuen.2012.12.017 